\title{
Soluble immune checkpoints are dysregulated in COVID-19 and heavy alcohol users with HIV infection
}

Wei $\mathrm{Li}^{1 *}$, Fahim Syed ${ }^{1 *}$, Richard $\mathrm{Yu}^{2}$, Jing Yang ${ }^{1}$, Ying Xia ${ }^{1,3 €}$, Ryan F. Relich${ }^{4}$, Shanxiang Zhang $^{4}$, Mandana Khalili5 ${ }^{5}$ Laurence Huang ${ }^{5}$, Melissa A. Kacena ${ }^{6}$, Xiaoqun Zheng ${ }^{3,7}$, Qigui Yu ${ }^{1 \#}$

${ }^{1}$ Department of Microbiology and Immunology, Indiana University School of Medicine, Indianapolis, IN 46202

${ }^{2}$ Department of Internal Medicine, School of Medicine, University of Nevada, Reno, NV 89502

${ }^{3}$ School of Laboratory Medicine, Wenzhou Medical University, Wenzhou, China

${ }^{4}$ Department of Pathology and Laboratory Medicine, Indiana University School of Medicine, Indianapolis, IN 46202

${ }^{5}$ Department of Medicine, University of California San Francisco, San Francisco, CA 94110

${ }^{6}$ Department of Orthopaedic Surgery, Indiana University School of Medicine, Indianapolis, IN 46202

${ }^{7}$ Department of Clinical Laboratory, the Second Affiliated Hospital and Yuying Children's Hospital of Wenzhou Medical University, Wenzhou, Zhejiang, China

*These authors contributed equally.

Co-corresponding authors.

Address correspondence to Dr. Qigui Yu (andyu@iupui.edu), Department of Microbiology and Immunology, Medical Science Building, MS267, Indiana University School of Medicine, 635

Barnhill Drive, Indianapolis, IN 46202, Tel: 317-274-2391, Fax: 317-278-3331. 
${ }^{€}$ Current address: Department of Chemistry and Molecular Biology, University of Gothenburg and Sahlgrenska University Hospital, Gothenburg, Sweden

Keywords: immune checkpoint, soluble immune checkpoint, COVID-19, HIV, heavy alcohol user, alcohol-associated liver disease, inflammation

Running title: Soluble immune checkpoints in health and disease

\section{Abbreviations}

ALD, alcohol-associated liver disease; APC, antigen-presenting cell; ART, antiretroviral therapy; BTLA, B- and T-lymphocyte attenuator; CTLA-4, cytotoxic T-lymphocyte-associated protein 4; GITR, glucocorticoid-induced tumor necrosis factor receptor-related protein; GITRL, glucocorticoid-induced tumor necrosis factor receptor-ligand; HBV, hepatitis B virus; HC, healthy control; HCC, hepatocellular carcinoma; HIV, human immunodeficiency virus; HVEM, herpesvirus entry mediator; ICP, immune checkpoint; ICOS, inducible T-cell costimulator; LAG3, lymphocyte-activation gene 3; LIGHT, homologous to lymphotoxin, exhibits inducible expression and competes with HSV glycoprotein D for binding to herpesvirus entry mediator, a receptor expressed on T lymphocytes; mICP, membrane-bound immune checkpoint; PD-1, programmed death 1; PD-L1, programmed death-ligand 1; PLHIV, people living with HIV; sICP, soluble immune checkpoint; TB, tuberculosis; TCR, T cell receptor; TIM-3, T-cell immunoglobulin and mucin domain 3; TIME, tumor immune microenvironment; TNFRSF, tumor necrosis factor receptor superfamily; TLR-2, Toll-like receptor-2. 
medRxiv preprint doi: https://doi.org/10.1101/2021.12.22.21268218; this version posted December 30, 2021. The copyright holder for this

\section{Abstract}

Immune checkpoints (ICPS) consist of paired receptor-ligand molecules that exert inhibitory or stimulatory effects on immune defense, surveillance, regulation, and self-tolerance. ICPs exist in both membrane and soluble forms in vivo and in vitro. Imbalances between inhibitory and stimulatory membrane-bound ICPS (mICPs) in malignant cells and immune cells in the tumor immune microenvironment (TIME) have been well documented. Blockades of inhibitory mICPs have emerged as an immense breakthrough in cancer therapeutics. However, the origin, structure, production regulation, and biological significance of soluble ICPs (sICPs) in health and disease largely remains elusive. Soluble ICPs can be generated through either alternative mRNA splicing and secretion or protease-mediated shedding from mICPs. Since sICPs are found in the bloodstream, they likely form a circulating immune regulatory system. In fact, there is increasing evidence that SICPs exhibit biological functions including (1) regulation of antibacterial immunity, (2) interaction with their mICP compartments to positively or negatively regulate immune responses, and (3) competition with their mICP compartments for binding to the ICP blocking antibodies, thereby reducing the efficacy of ICP blockade therapies. Here, we summarize current data of SICPs in cancer and infectious diseases. We particularly focus on SICPS in COVID-19 and HIV infection as they are the two ongoing global pandemics and have created the world's most serious public health challenges. A "storm" of sICPs occurs in the peripheral circulation of COVID-19 patients and is associated with the severity of COVID19. Similarly, sICPs are highly dysregulated in people living with HIV (PLHIV) and some sICPS remain dysregulated in PLHIV on antiretroviral therapy (ART), indicating these sICPs may serve as biomarkers of incomplete immune reconstitution in PLHIV on ART. We reveal that HIV infection in the setting of alcohol abuse exacerbates SICP dysregulation as PLHIV with heavy alcohol consumption have significantly elevated plasma levels of many sICPs. Thus, both stimulatory and inhibitory sICPS are present in the bloodstream of healthy people and their balance can be disrupted under pathophysiological conditions such as cancer, COVID-19, HIV 
medRxiv preprint doi: https://doi.org/10.1101/2021.12.22.21268218; this version posted December 30, 2021. The copyright holder for this preprint (which was not certified by peer review) is the author/funder, who has granted medRxiv a license to display the preprint in perpetuity. All rights reserved. No reuse allowed without permission.

infection, and alcohol abuse. There is an urgent need to study the role of sICPs in immune regulation in health and disease. 
medRxiv preprint doi: https://doi.org/10.1101/2021.12.22.21268218; this version posted December 30, 2021. The copyright holder for this preprint (which was not certified by peer review) is the author/funder, who has granted medRxiv a license to display the preprint in perpetuity.

\section{Introduction}

Immune checkpoints (ICPS) consist of paired receptor-ligand molecules that exert inhibitory or stimulatory effects on immune defense, surveillance, regulation, and self-tolerance ${ }^{1-}$ 5. Under normal circumstances, ICPs regulate the breadth, magnitude, and duration of the immune responses against malignancy and infection while protecting tissues from excessive insult. However, in certain pathological situations such as cancer or persistent infection, the balance between ICP stimulatory and inhibitory signals becomes dysregulated ${ }^{1-7}$. Malignant cells can dysregulate the expression of ICPS on the surface of immune cells to evade or subvert the immune response, leading to insufficiency or failure of anti-tumor immune attacks. The upregulated expression of inhibitory ICPS, including CTLA-4, PD-1, TIM-3, and LAG-3 has been found on the surface of both CD4 and CD8 T cells in cancer patients ${ }^{6,8-10}$. These important findings have laid the foundation for the clinical development of ICP blockade therapies, which abrogate ICP inhibitory signals, restoring and enhancing the anti-tumor activity of cytotoxic T lymphocytes (CTLs) 3,5,11,12. Since 2011, ICP blockers targeting CTLA-4, PD-1, and PD-L1 have yielded unprecedented responses in a portion of cancer patients, leading to seven FDAapproved ICP blocking antibodies against these ICPs, including one anti-CTLA-4 antibody (Ipilimumab), three anti-PD-1 antibodies (Nivolumab, Pembrolizumab, and Cemiplimab), and three anti-PD-L1 antibodies (Avelumab, Durvalumab, and Atezolizumab), for treating several types of cancer such as melanoma and lung cancer ${ }^{5,13-15}$.

Similar to malignant cells, several pathogens, including HIV (the human immunodeficiency virus), HBV (hepatitis B virus), TB (tuberculosis), and malaria have been demonstrated to dysregulate ICPs to limit host-protective CTLs $s^{6,7,16,17}$. For example, in antiretroviral therapy (ART)-naïve people living with HIV (PLHIV), there is upregulated expression of multiple inhibitory ICPs including CTLA-4, PD-1, TIM-3, and LAG-3 on total and HIV-specific CD4 and CD8 T cells ${ }^{6-8,17-21}$, which is associated with an accelerated decline in the number of CD4 T cells in PLHIV ${ }^{8,22}$. Following ART, expression of these ICPs on the surface of $T$ cells declines, but 
medRxiv preprint doi: https://doi.org/10.1101/2021.12.22.21268218; this version posted December 30, 2021. The copyright holder for this

remains elevated when compared with healthy controls ${ }^{8-10}$. Importantly, expression of inhibitory ICPs can be used as surrogate immunological biomarkers of ART effectiveness. In ART-treated PLHIV, PD-1 expression on CD8 T cells has been associated with impaired reconstitution of CD4 T cells and a shorter time to viral rebound after stopping ART ${ }^{23,24}$. In addition, CD4 T cells expressing high levels of PD-1, LAG-3, and TIGIT alone or in combination are enriched for integrated HIV DNA during ART ${ }^{25,26}$. Furthermore, most CD4 T cells expressing at least one of these ICPs, carry inducible and replication-competent HIV genomes ${ }^{25}$. Thus, CD4 T cells expressing inhibitory ICPs such as PD-1 and LAG-3 contribute to HIV persistence during ART. In vitro and ex vivo studies have shown that blocking antibodies against either PD-1, CTLA-4, LAG-3, or TIM-3 can significantly restore the proliferative capacities and functions of T cells and B cells from PLHIV on ART ${ }^{21}$. Currently, there are several clinical trials in PLHIV with and

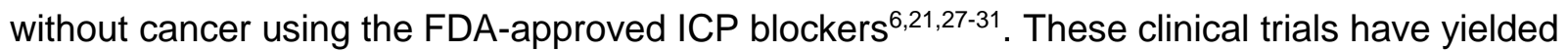
mixed results ranging from little therapeutic benefit to significant expansions of HIV-specific CD4 and CD8 T cells in a subset of participants ${ }^{27-32}$, indicating ICP blockade for the treatment of HIV infection needs further study.

ICP molecules exist in both membrane and soluble forms in vivo and in vitro ${ }^{33-44}$. Similar to membrane-bound ICPs (mICPs), soluble ICPs (SICPs) are also present in normal physiological conditions and highly dysregulated in patients with cancer, viral infections, or ALD (alcoholassociated liver disease) $)^{33-45}$. Soluble ICPs can be generated through either alternative mRNA splicing and secretion or protease-mediated shedding from mICPs by actions of matrix metalloproteinases (MMPs) ${ }^{44,46}$. Although the detailed structure, production regulation, function, and clinical relevance of sICPs largely remain unknown, many SICPs exist in native forms that exhibit biological functions such as regulation of antibacterial immunity ${ }^{42,46}$. Since sICPs are paired receptor-ligand molecules and circulate in the bloodstream, they likely form a circulating immune regulatory system. In addition, increasing evidence has shown that sICPs interact with their mICP compartments to positively or negatively regulate immune responses ${ }^{43}$. Furthermore, 
medRxiv preprint doi: https://doi.org/10.1101/2021.12.22.21268218; this version posted December 30, 2021. The copyright holder for this

sICPs can compete with their mICP compartments for binding to the ICP blocking antibodies, thereby interrupting the efficacy of ICP blockade therapies. Thus, there is an urgent need to study the role of SICPS in immune regulation in health and disease. Here, we summarize current data of sICPs in cancer and infectious diseases. We particularly focus on sICPs in COVID-19 and HIV infection as they are the two ongoing global pandemics and have created the world's most serious public health and development challenges.

\section{Soluble immune checkpoints in the peripheral circulation of healthy people}

As described in our recent report ${ }^{45}$, we used a multiplex immunoassay (the Human Immuno-Oncology Checkpoint Protein Panel, MilliporeSigma, Burlington, MA) to simultaneously quantify plasma concentrations of 16 sICPs (sBTLA, sCD27, sCD28, sCD40, sCD80/B7-1, sCD86/B7-2, sCTLA-4, sGITR, sGITRL, sHVEM, sICOS, SLAG-3, sPD-1, sPD-L1, sTIM-3, and sTLR-2) in healthy blood donors. Plasma levels of two additional ICPS (SCD160 and SLIGHT) were quantified using the Human CD160 Matched ELISA Antibody Pair Set (Sino Biological, Beijing, China) and the Human LIGHT Duoset ELISA Kit (R\&D Systems, Minneapolis, MN), respectively. We found that, except for SGITR and SLIGHT, which were only detected in 30-50\% of plasma samples, all other 16 sICPs were steadily detected in plasma samples from all healthy blood donors (Table 1). These sICPs could be generated through either alternative mRNA splicing and secretion or protease-mediated shedding from mICPs by actions of MMPs $^{44,46}$. Several studies have demonstrated that sICPs are present in the peripheral blood as the native polypeptide products of their genes and have biological functions. For example, CTLA-4, also known as CD152, is a member of the immunoglobulin (Ig) gene superfamily ${ }^{47}$. CTLA4 is constitutively expressed in regulatory $\mathrm{T}$ cells but can be upregulated in conventional $\mathrm{T}$ cells after activation ${ }^{47,48}$. CTLA-4 and CD28 are homologous receptors that share a pair of ligands (B7-1 and B7-2) expressed on the surface of antigen-presenting cells (APCs), but mediate opposing functions in T-cell activation ${ }^{48}$. CTLA-4 interacts with its ligands to inhibit T- 
medRxiv preprint doi: https://doi.org/10.1101/2021.12.22.21268218; this version posted December 30, 2021. The copyright holder for this

cell responses ${ }^{48}$, while CD28 acts as a major co-stimulatory receptor in promoting full activation of $\mathrm{T}$ cells in response to $\mathrm{T}$ cell receptor (TCR) engagement ${ }^{49}$. As shown in Table 1, plasma levels of SCTLA-4 in healthy individuals were detected at a median concentration of $31 \mathrm{pg} / \mathrm{mL}$ with the interquartile ranges of $12-81 \mathrm{pg} / \mathrm{mL}(\mathrm{n}=39)$, which are higher than the detection limit $(9.3 \mathrm{pg} / \mathrm{mL})$ of the multiplex immunoassay. These results argue against a previous report showing that circulating CTLA-4 was undetectable in healthy volunteers using an enzyme immunoassay $(E I A)^{44}$. This is because the EIA has limited detection sensitivity $(\geq 4 \mathrm{ng} / \mathrm{mL})^{44}$, which is insufficiently sensitive for the detection of SCTLA-4 concentrations in healthy people. Immunoprecipitation and Western blotting analyses of serum SCTLA-4 revealed a polypeptide consistent with the predicted size $(23 \mathrm{kDa})$ from an alternative transcript of the CTLA-4 gene, suggesting SCTLA-4 is present as a native molecule rather than a product of proteolytic digestion or shedding of mCTLA-4 ${ }^{44}$. Functional studies have shown that SCTLA-4 immunoreactivity can be blocked by B7.1 (also known as CD80), one of its known ligands. This supports the notion that SCTLA-4 is present as a soluble functional molecule. Thus, SCTLA-4 likely has important immunoregulatory functions, which is similar to soluble cytokine receptors such as soluble forms of TNF receptor, IL-2 $\alpha$ receptor, IL-4 receptor, and IL-7 receptor that exist in the biological fluids and regulate cytokine activity in vitro and in vivo $0^{50-55}$.

In contrast to SCTLA-4, several sICPs including SHVEM (also known as TNFRSF14 or CD270), sCD160, sLAG-3, and sTIM-3 were present at high concentrations (Table 1) in healthy people. These are potent inhibitory ICPS. HVEM was initially identified as the receptor of herpes simplex virus 1 (HSV-1) through binding to the HSV-1 glycoprotein D $(g D)^{56}$. Since then, HVEM has been identified as a co-signaling molecular switch through interacting with BTLA (also known as CD272), CD160, and LIGHT ${ }^{57}$. In addition, HVEM can bind to SALM5 (synaptic adhesion-like molecule 5) to regulate neuroinflammation ${ }^{58}$. We have recently reported that recombinant SHVEM affects TNF- $\alpha$ and IFN-Y production by anti-CD3/anti-CD28-stimulated T cells from healthy volunteers ${ }^{45}$, indicating SHVEM may act as a circulating immune regulator. 
medRxiv preprint doi: https://doi.org/10.1101/2021.12.22.21268218; this version posted December 30, 2021. The copyright holder for this

Like SCTLA-4 and SHVEM, other sICPs such as SLAG-3, sTIM-3, SPD-1, and SPD-L1 are biologically active and participate in immune regulation ${ }^{39,59-61}$. Thus, the majority (if not all) of ICPs have soluble forms that are detectable in the peripheral blood of healthy individuals. Different sICPs are likely produced at different levels and at distinct checkpoints to fine-tune immune homeostasis in health, although their origin, production regulation, and biological function are yet to be discovered. Of note, these data related to plasma sICPs were obtained from adults with a median age of 42 years (26-52) and $64 \%$ were from males ${ }^{45}$. Future study is needed to investigate whether SICP levels and functions in healthy people are affected by age, gender, and race.

\section{Soluble immune checkpoints in cancer}

ICPs act as gatekeepers for immune responses and play a central role in immune homeostasis that is maintained by a precise balance between stimulatory and inhibitory ICPs on the surface of effector and regulatory immune cells. The immune homeostasis is a tightly regulated network which fails during tumor development due to an imbalance between inhibitory and stimulatory ICPS. Indeed, high levels of inhibitory ICPS on the surface of tumor cells is a hallmark of the tumor immune microenvironment (TIME) that is infiltrated with many types of innate and adaptive immune cells ${ }^{62}$. Increased inhibitory ICPS are responsible for tumor immune escape and thereby have become major targets for cancer immunotherapy ${ }^{5,13-15}$.

While mICPs have been extensively studied in cancer immunity and cancer immunotherapy, the origin, production regulation, and biological significance of sICPs largely remains elusive. Due to their function in both positive and negative immune regulation, sICPs and their levels change in the peripheral blood, which may affect the development, prognosis, and treatment of cancer. Studies have shown that plasma or serum levels of sICPs can serve as biomarkers and/or predictors of cancer patient outcomes or therapeutic responses ${ }^{43,63}$. Plasma or serum levels of numerous sICPs including sPD-L1, sPD-1, sLAG-3, sTIM-3, sCTLA- 
medRxiv preprint doi: https://doi.org/10.1101/2021.12.22.21268218; this version posted December 30, 2021. The copyright holder for this

4, sHVEM, sCD80, sCD86, SCD27, sCD40, and sBTLA are highly elevated in patients with various types of tumors and serve as prognostic markers for solid tumors such as non-small cell lung cancer, gastric cancer, colon cancer, and cervical cancer ${ }^{42,60,64-67}$. Soluble ICPs are also biologically active in cancer patients. Studies have revealed that plasma/serum levels of SCD40L are highly elevated in patients with lung cancer and undifferentiated nasopharyngeal carcinoma ${ }^{68,69}$. The elevated SCD40L in cancer patients is likely derived from activated platelets rather than T cells, because cancer patients have significant platelet activation, but inadequate T-cell activation ${ }^{70-72}$. A functional study has shown that the upregulated SCD40L seen in cancer patients exerts an immunosuppressive effect through enhancement of MDSC (myeloid-derived suppressor cell)-mediated suppression of T cell proliferation and IFN-ץ production, expansion of regulatory $\mathrm{T}$ cells (Treg), and enrichment of PD-1+ ${ }^{+}$cells ${ }^{73}$. On the other hand, SPD-1 is likely generated through mRNA splicing and secretion, as four PD-1 splice variants have been identified ${ }^{74}$. In vitro and in vivo studies have shown SPD-1 is able to bind its membrane-bound ligands (mPD-L1 and mPD-L2) to block mPD-1/mPD-L1/mPD-L2 interaction, thereby restoring T cell immunity ${ }^{60}$. Indeed, local delivery of SPD-1 in the tumor microenvironment through adenoassociated virus-mediated delivery vector induces antitumor immunity through improving $\mathrm{T}$ cell function $^{75,76}$. The origin, production regulation, function, and biological significance of sICPs in tumors have been systematically reviewed ${ }^{43,60,77,78}$. Collectively, the levels of sICPs in the peripheral circulation in cancer patient are frequently altered, which likely has clinical significances. That said, a better understanding of the underlying mechanisms of the sICP network could lay the foundation for the development of new strategies for treating cancers with immunotherapies.

\section{Soluble immune checkpoints in patients with COVID-19}

Two recent studies, reported by Kong Y et al. (2020) and Avendano-Ortiz J et al. (2021), have demonstrated that a "storm" of sICPs occurs in COVID-19 patients and is associated with 
medRxiv preprint doi: https://doi.org/10.1101/2021.12.22.21268218; this version posted December 30, 2021. The copyright holder for this

the severity of COVID-1979,80. The Kong study quantified 14 SICPs including SBTLA, SCTLA-4, sGITR, sHVEM, SIDO, sLAG-3, sPD-1, sPD-L1, sPD-L2, sTIM-3, sCD27, sCD28, sCD80, and s4-1BB in the serum samples from patients with asymptomatic, mild/moderate, and severe/critical COVID-19 using the ProcartaPlex Human ImmunoOncology Checkpoint Panel (Invitrogen, Carlsbad, CA) ${ }^{79}$, while the Avendano-Ortiz study quantified 9 sICPs including sCD25, sCD86, sCTLA-4, Galectin-9, sLAG-3, sPD-1, sPD-L1, sTim-3, and s4-1BB using the LEGENDplex HU Immune Checkpoint Panel 1 (BioLegend, San Diego, CA) ${ }^{80}$. After merging the overlapping 6 sICPs that were detected in both studies, a total of 17 sICPs including sBTLA, sCTLA-4, sGalectin-9, sGITR, sHVEM, sIDO, sLAG-3, sPD-1, sPD-L1, sPD-L2, sTIM-3, sCD25, sCD27, sCD28, sCD80, sCD86, and s4-1BB were studied in the serum or plasma samples from COVID-19 patients ${ }^{79,80}$. The Kong study showed that, except for SPD-L2, each of the other 13 sICPs was significantly higher in the severe/critical group than in the mild/moderate and asymptomatic groups ${ }^{79}$. On the other hand, the Avendano-Ortiz study showed that plasma levels of sCD25, sCD86, Galectin-9, sPD-1, sPD-L1, and sTim-3, but not SLAG-3, sCTLA-4, and s4-1BB, were significantly higher in the severe/critical group than in the mild/moderate groups ${ }^{80}$. Therefore, both studies demonstrated that the serum or plasma levels of SPD-1, sPD-L1, and sTIM-3 were significantly higher in the severe/critical group than in the mild/moderate and asymptomatic groups, but their data conflicted regarding the serum or plasma levels of sLAG-3, SCTLA-4, and S4-1BB between healthy controls and COVID-19 patients ${ }^{80}$. The Kong study also showed that serum levels of 11 sICPs (sGITR, s4-1BB, sTIM-3, sCD27, sLAG-3, sPD-1, sCD28, sCTLA-4, SBTLA, SHVEM, and SCD80) were persistently higher in severe/critical patients than in mild/moderate cases during hospitalization. In addition, the levels of 8 sICPS (SIDO, sGITR, s4-1BB, sTIM-3, sCD27, sLAG-3, sPD-1, and SCD28) were negatively correlated with absolute counts of CD4 and CD8 T cells. The Avendano-Ortiz study also demonstrated that plasma levels of SCD25, sTIM-3, Galectin-9, and SPD-L1, but not SCD86, showed a negative correlation with the absolute lymphocyte count (ALC). These results suggest that sICPS are dysregulated in 
medRxiv preprint doi: https://doi.org/10.1101/2021.12.22.21268218; this version posted December 30, 2021. The copyright holder for this

COVID-19 and SICP dysregulation may be linked to COVID-19 lymphopenia, an abnormal reduction in lymphocyte numbers. Lymphopenia is a prominent clinical feature of COVID-19 patients and has been associated with the severity of COVID-1981-86. Indeed, non-survivors of COVID-19 have a significantly lower lymphocyte count than survivors ${ }^{82,87}$. The absolute cell counts of lymphoid lineage cells, including T cells, B cells, and NK cells, are abnormally reduced with a more pronounced decrease in CD8 T cells ${ }^{88-90}$. In contrast, myeloid lineage cells such as neutrophils are highly increased in the blood of patients with severe COVID-1983, which is noted as a major clinical feature of severe COVID-1991. The mechanisms of COVID-19 lymphopenia remain unclear, although several hypotheses are proposed including a cytokine storm impact ${ }^{92-}$ ${ }^{94}$, direct infection of immune cells ${ }^{95}$, overaggressive T cell responses ${ }^{96}$, and lymphocyte infiltration and sequestration in the lungs ${ }^{87}$. However, these hypotheses have been challenged, because (1) most COVID-19 patients do not have remarkably high levels of inflammatory cytokines, as only 4\% of critically ill COVID-19 patients develop cytokine storm symptom (CSS) and anti-CSS medications have no benefit for most COVID-19 patients ${ }^{83,97-101}$, (2) direct viral infection is an unlikely cause of immune cell loss ${ }^{102}$, as infectious SARS-CoV-2 has not been successfully isolated from peripheral blood cells in COVID-19 patients ${ }^{94},(3)$ the overall magnitude of the T cell response in COVID-19 patients is either insufficient or excessive remains debated ${ }^{96}$, as $T$ cell responses are insufficient in some COVID-19 patients, but excessive in others ${ }^{96}$, and (4) post-mortem biopsies from COVID-19 patients with marked lymphopenia reveal prominent infiltration of neutrophils, but neither T cells nor B cells, in the lungs ${ }^{103-106}$. Thus, studies are urgently needed to determine the cause and impact of the commonly observed lymphopenia in patients with severe COVID-19, and whether dysregulated SICPs are associated with the pathogenesis of COVID-19 lymphopenia.

We also used a multiplex immunoassay (the Human Immuno-Oncology Checkpoint Protein Panel, MilliporeSigma, Burlington, MA) to simultaneously quantify the concentrations of 16 sICPs in plasma samples from healthy controls $(n=23)$ and patients with asymptomatic 
medRxiv preprint doi: https://doi.org/10.1101/2021.12.22.21268218; this version posted December 30, 2021. The copyright holder for this

$(n=15)$ or hospitalized (severe/critical) COVID-19 (n=24). Among these 16 sICPs, 4 (sCD40, sGITRL, sICOS, and STLR-2) were not previously studied in COVID-19 patients, while 12 were already tested in the two studies by Kong and Avendano-Ortiz et al. In our studies, the healthy control subjects were matched with the COVID-19 patients in terms of age, sex, and race. We found that plasma levels of the majority of 16 sICPS were significantly higher in COVID-19 patients when compared with healthy controls (data not shown). The 4 sICPs (sCD40, sGITRL, sICOS, and STLR-2) that had not previously been studied in COVID-19 were significantly higher in the plasma from patients with asymptomatic or severe/critical COVID-19 when compared with healthy controls (Fig. 1A). Plasma levels of sGITRL, sICOS, and STLR-2, but not SCD40 were further elevated in severe/critical COVID-19 patients than in asymptomatic cases (Fig. 1A). We also found that SCTLA-4 and SLAG-3, 2 sICPs that were studied by Kong and Avendano-Ortiz et al. with conflicting results, were elevated in plasma from patients with severe/critical COVID19 when compared with healthy controls (Fig. 1B), which is in agreement with Kong's results.

Taken together, a storm of sICPS occurs in the peripheral circulation of COVID-19 patients and is associated with the disease severity. The circulating SICP levels on admission appear to be better mortality predictors than inflammatory cytokines and chemokines ${ }^{80}$, and thereby can potentially serve as biomarkers of COVID-19 progress and outcome. Given that some, if not all, sICPs are biological active, they may also serve as circulating immune regulators or pharmaceutical targets for COVID-19 therapy. To this end, mechanistic studies and large-scale, cross-sectional and longitudinal studies are needed to investigate the origin, production regulation, and clinical significance of SICPs in patients with COVID-19.

\section{Soluble immune checkpoints in people living with HIV (PLHIV)}

Chronic immune activation and exhaustion are important features of persistent viral infections such as infection with HIV. Indeed, immune exhaustion represents a barrier to effective and specific immunity against HIV infection. Chronic immune activation and exhaustion 
medRxiv preprint doi: https://doi.org/10.1101/2021.12.22.21268218; this version posted December 30, 2021. The copyright holder for this

are at least in part attributed to the dysregulation of ICPs. In addition to mICPs that have been demonstrated to play a critical role in immune homeostasis in PLHIV, sICPs may also be dysregulated in PLHIV and thereby contribute to immune exhaustion in PLHIV. A recent study used ELISA to quantify plasma levels of SPD-L1 in PLHIV and healthy controls and found that plasma levels of SPD-L1 were significantly elevated in PLHIV and remained high despite control of HIV infection by $\mathrm{ART}^{107}$. In addition, PLHIV on ART with virological failure had the highest plasma levels of SPD-L1 $1^{107}$. Thus, SPD-L1 in the peripheral blood represents a potential biomarker of immune exhaustion and virological failure in PLHIV.

Here, we simultaneously quantified plasma levels of 16 sICPs from 23 healthy controls, 46 PLHIV who were ART-naïve, and 65 PLHIV who were on ART using a multiplex immunoassay as detailed above. These three groups of study subjects were matched in terms of demographic parameters including age, gender, and race. As shown in Fig. 2, except GITR which was only detected in $34.8 \%(8 / 23)$ of healthy controls, each of the other 15 sICPs was detectable in the plasma samples from healthy controls, indicating that they could play biological roles in immune homeostasis under physiologic conditions. Compared to healthy controls, ART-naïve PLHIV had significantly higher plasma levels of the 15 sICPs tested. Specifically, only sTIM-3 was not elevated in ART-naïve PLHIV. In comparison to healthy controls, PLHIV on ART only had higher plasma levels of 3 sICPs (sCD40, sCTLA-4, and sHVEM) (Fig. 2). These findings appear to indicate that ART effectively, but not completely, restores ICP homeostasis. Among these 3 sICPs that remained at higher levels in the peripheral blood of PLHIV on ART, SHVEM and sCD40 were not affected by ART, while SCTLA-4 was dramatically reduced, but did not return to a normal level (Fig. 2). Both CD40 (also known as TNFRSF5) and HVEM (also known as TNFRSF14) are members of the tumor necrosis factor receptor superfamily. CD40 is a costimulatory molecule that is mainly expressed on the surface of APCs such as dendritic cells, monocytes/macrophages, and B cells. CD40 is required for APC activation via binding to CD154 (also known as CD40 ligand or CD40L) on T cells. CD40-CD40L interaction leads to the 
medRxiv preprint doi: https://doi.org/10.1101/2021.12.22.21268218; this version posted December 30, 2021. The copyright holder for this

initiation of bidirectional intracellular signaling in both $\mathrm{CD} 40^{+} \mathrm{APCs}$ and $\mathrm{CD} 4 \mathrm{LL}^{+} \mathrm{T}$ cells, resulting in APC activation and T cell responses ${ }^{108-110}$. Dysregulation of CD40/CD40L expression and interactions contributes to the severity in numerous diseases such as HIV infection ${ }^{111-113}$, cancer $^{108,114}$, and autoimmune disorders ${ }^{115-117}$. However, the role of SCD40 in the peripheral circulation of PLHIV largely remains elusive. We found that ART-naïve PLHIV had excessive production of SCD40, which was minimally affected by ART, suggesting that circulating SCD40 may represent an indicator of dysregulation of APC and T cell function that is a hallmark of HIVassociated deficiency in cell-mediated immunity.

Similar to SCD40, sHVEM was also excessively produced in PLHIV and was barely affected by ART (Fig. 2). HVEM serves as a shared receptor/ligand for stimulatory and inhibitory ligands/receptors, including LIGHT, BTLA, and CD160 that are expressed on both hematopoietic and non-hematopoietic cells. HVEM acts as a bifunctional ligand/receptor that exhibits costimulatory signals upon binding to LIGHT and co-inhibitory signals upon binding to BTLA or CD160 ${ }^{118,119}$. Due to its role of bifunctional ligand/receptor, HVEM serves as a molecular switch between stimulatory and inhibitory signaling ${ }^{120,121}$, thereby playing a unique role in immune homeostasis. We have recently reported that expressions of both SHVEM and mHVEM were highly dysregulated in heavy alcohol users with ALD, specifically alcoholic hepatitis $(A H)$, when compared with heavy alcohol users without $A H^{45}$. Plasma levels of upregulated SHVEM in AH patients remained high for 6 months of complete alcohol abstinence $^{45}$, indicating SHVEM might serve as a prognostic marker for $\mathrm{AH}$. We also found that sHVEM-his, consisting of the soluble extracellular domain of human mHVEM linked to a polyhistidine tag at the C-terminus, significantly inhibited TCR-induced TNF-a production by both CD4 T cells and CD8 T cells from AH patients and healthy controls ${ }^{45}$, indicating sHVEM plays an inhibitory role in HVEM axis-mediated TNF- $\alpha$ production. Currently, the regulation and function of SHVEM in HIV immunopathogenesis is not known. Thus, studies are needed to 
medRxiv preprint doi: https://doi.org/10.1101/2021.12.22.21268218; this version posted December 30, 2021. The copyright holder for this

elucidate the mechanisms of action for the SHVEM axis and the interplay between SHVEM and mHVEM in HIV infection.

\section{Soluble immune checkpoints in heavy alcohol users with HIV infection}

Alcohol abuse and HIV infection are both major health issues worldwide. Globally, more than 2 billion people consume alcohol on a regular basis, and approximately 76 million suffer from alcohol-related disorders ${ }^{122,123}$. Long-term heavy alcohol users develop a spectrum of ALD, ranging from $\mathrm{AH}$, fibrosis/cirrhosis, to hepatocellular carcinoma $(\mathrm{HCC})^{124}$. Alcohol overconsumption contributes to $5.1 \%$ of the global burden of diseases and causes approximately 3.3 million deaths every year ${ }^{125,126}$. HIV is the causative agent of AIDS and has claimed over 36 million lives with an estimated 38 million PLHIV worldwide at the end of 2020127. Alcohol overconsumption is common among PLHIV and adversely influences the health outcomes by increasing HIV-associated comorbidities such as liver disease, cardiovascular disease, pulmonary disease, bone disease, and cancer ${ }^{128-130}$. It is well known that alcohol overconsumption and HIV infection independently damage the gastrointestinal (GI) tract mucosal barrier, leading to a leaky gut that allows microbial translocation and accumulation of microbial components such as lipopolysaccharide (LPS) in the blood. Specifically, alcohol disrupts gap junction integrity of gut mucosal epithelial cells, leading to increased GI permeability and translocation of microbial components such as LPS from the GI tract into the blood and liver ${ }^{131-133}$. Alcohol-induced microbial translocation has been considered a major driver of chronic immune activation and inflammation in AH patients ${ }^{134-137}$. In PLHIV, microbial translocation is a cause of chronic immune activation and inflammation, which is a hallmark of progressive HIV infection and a stronger predictor of disease outcome compared to plasma viral load $^{138,139}$. We therefore hypothesize that alcohol overconsumption and HIV infection exacerbate microbial translocation, immune dysregulation, and inflammation, thereby accelerating disease progression of HIV infection and ALD. To test this hypothesis, we 
medRxiv preprint doi: https://doi.org/10.1101/2021.12.22.21268218; this version posted December 30, 2021. The copyright holder for this

established a cohort of heavy alcohol users with and without HIV infection. We analyzed and compared the profiles of SICPs in the peripheral blood in heavy drinkers without overt ALD (HDC) versus PLHIV on ART (HIV) versus PLHIV on ART who were heavy drinkers, but did not have ALD (HDC+HIV). We found that plasma levels of all 16 sICPs were similar between HDC and HIV groups (Table 2). Fourteen out of sixteen sICP examined were dramatically elevated in the peripheral blood in HDC+HIV when compared with either HDC or HIV (Table 2). SCD27 and sTIM-3 were not elevated in HDC+HIV compared with either HDC or HIV (Table 2). These results indicate that sICPs were highly dysregulated in HDC+HIV even though these individuals had no clinical evidence of overt ALD and their liver enzyme parameters including the circulating levels of AST and ALT and AST:ALT ratio were similar to healthy individuals (data not shown). Previous studies from our group and others have demonstrated that chronic excessive drinking leads to immune abnormalities in heavy drinkers even when there are no obvious signs of clinical liver disease $\mathrm{i}^{137,140-142}$. HDCs have increased bacterial translocation as they have higher serum levels of LPS and markers of monocyte/macrophage activation (sCD14 and SCD163) than non-excessive drinkers ${ }^{141}$. In addition, mucosal-associated invariant T (MAIT) cells in the peripheral blood are significantly decreased in HDCs compared to healthy controls ${ }^{142}$. Moreover, HDCs have increased levels of MAIT activation-associated cytokines such as IL-18 and IL-12 ${ }^{142}$. MAIT cells are innate-like lymphocytes that are highly enriched in liver, mucosa, and peripheral blood, and play a protective role in antimicrobial immunity ${ }^{143,144}$. These results highlight the presence of immune dysregulation in HDCs. HIV infection and alcohol abuse dramatically exacerbate immune abnormalities such as SICP dysregulation. Future study is needed to investigate the mechanisms underlying exacerbated SICP dysregulation in heavy drinkers with HIV infection.

\section{Conclusion}


medRxiv preprint doi: https://doi.org/10.1101/2021.12.22.21268218; this version posted December 30, 2021. The copyright holder for this

ICP molecules exist in both membrane and soluble forms in vivo and in vitro. Imbalance between inhibitory and stimulatory mICPs in malignant cells and immune cells in tumor microenvironment has been well documented and blockade of inhibitory mICPs has emerged as an immense breakthrough in cancer therapeutics. While mICPs have been extensively studied, their soluble compartments have not been adequately studied. sICPS can be generated through either alternative mRNA splicing and secretion or protease-mediated shedding from mICPs. However, the cellular resource, structure, production regulation, and biological significance of SICPS in health and disease largely remain elusive. Here, we summarize current data of sICPS in cancer and infectious diseases. A storm of sICPS occurs in the peripheral circulation of COVID-19 patients and is associated with the severity of COVID-19. Similarly, sICPs are highly dysregulated in PLHIV and some sICPs remain dysregulated in PLHIV on ART, indicating these SICPS may serve as biomarkers of incomplete immune reconstitution for PLHIV on ART.

Strikingly, HIV infection and alcohol abuse dramatically exacerbate SICP dysregulation. Thus, both stimulatory and inhibitory sICPS are present in the bloodstream of healthy people and their balance can be disrupted under pathophysiological conditions such as cancer, COVID-19, HIV infection, and alcohol abuse. Further studies are needed to investigate whether sICPs act as critical circulating immune regulators in health and disease.

\section{Notes}

Study Subjects and Ethical Considerations. This study was performed with the approval of the Institutional Review Board at Indiana University School of Medicine and University of California San Francisco. Blood samples were drawn after each participant provided a written informed consent form.

Disclaimer. The content of this article is solely the responsibility of the authors and does not necessarily represent the official views of the National Institutes of Health $(\mathrm{NIH})$ or the Bill and Melinda Gates Foundation. 
medRxiv preprint doi: https://doi.org/10.1101/2021.12.22.21268218; this version posted December 30, 2021. The copyright holder for this preprint (which was not certified by peer review) is the author/funder, who has granted medRxiv a license to display the preprint in perpetuity.

All rights reserved. No reuse allowed without permission.

Financial support. This work was supported by the National Institute on Alcohol Abuse and Alcoholism (grant number UH2AA026218 to Q. Y.); the Bill and Melinda Gates Foundation (grant number OPP1035237 to Q. Y.); the Indiana Biobank and the Indiana Clinical and Translational Sciences Institute funded by the NIH (grant number UL1TR002529); and the National Center for Advancing Translational Sciences, Clinical and Translational Sciences

Award. Dr. Khalili was also in part supported by the National Institute of Alcohol Abuse and Alcoholism (grant number K24AA022523).

Potential conflicts of interest. All authors: No reported conflicts of interest. 
medRxiv preprint doi: https://doi.org/10.1101/2021.12.22.21268218; this version posted December 30, 2021. The copyright holder for this preprint (which was not certified by peer review) is the author/funder, who has granted medRxiv a license to display the preprint in perpetuity. All rights reserved. No reuse allowed without permission.

\section{Reference}

1. Sanmamed, M.F. \& Chen, L. A Paradigm Shift in Cancer Immunotherapy: From Enhancement to Normalization. Cell 175, 313-326 (2018).

2. Chen, L. \& Flies, D.B. Molecular mechanisms of T cell co-stimulation and co-inhibition. Nat Rev Immunol 13, 227-242 (2013).

3. Sharma, P. \& Allison, J.P. The future of immune checkpoint therapy. Science 348, 56-61 (2015).

4. Ishida, Y., Agata, Y., Shibahara, K. \& Honjo, T. Induced expression of PD-1, a novel member of the immunoglobulin gene superfamily, upon programmed cell death. EMBO J 11, 3887-3895 (1992).

5. Wei, S.C., Duffy, C.R. \& Allison, J.P. Fundamental Mechanisms of Immune Checkpoint Blockade Therapy. Cancer Discov 8, 1069-1086 (2018).

6. Wykes, M.N. \& Lewin, S.R. Immune checkpoint blockade in infectious diseases. Nat Rev Immunol 18, 91-104 (2018).

7. Dyck, L. \& Mills, K.H.G. Immune checkpoints and their inhibition in cancer and infectious diseases. Eur J Immunol 47, 765-779 (2017).

8. Trautmann, L., et al. Upregulation of PD-1 expression on HIV-specific CD8+ T cells leads to reversible immune dysfunction. Nat Med 12, 1198-1202 (2006).

9. Kaufmann, D.E., et al. Upregulation of CTLA-4 by HIV-specific CD4+ T cells correlates with disease progression and defines a reversible immune dysfunction. Nat Immunol 8, 1246-1254 (2007).

10. Chew, G.M., et al. TIGIT Marks Exhausted T Cells, Correlates with Disease Progression, and Serves as a Target for Immune Restoration in HIV and SIV Infection. PLoS Pathog 12, e1005349 (2016).

11. Topalian, S.L., Drake, C.G. \& Pardoll, D.M. Immune checkpoint blockade: a common denominator approach to cancer therapy. Cancer Cell 27, 450-461 (2015).

12. Pardoll, D.M. The blockade of immune checkpoints in cancer immunotherapy. Nat Rev Cancer 12, 252-264 (2012).

13. Hargadon, K.M., Johnson, C.E. \& Williams, C.J. Immune checkpoint blockade therapy for cancer: An overview of FDA-approved immune checkpoint inhibitors. Int Immunopharmacol 62, 29-39 (2018).

14. Berghoff, A.S., Venur, V.A., Preusser, M. \& Ahluwalia, M.S. Immune Checkpoint Inhibitors in Brain Metastases: From Biology to Treatment. Am Soc Clin Oncol Educ Book 35, e116-122 (2016).

15. Vaddepally, R.K., Kharel, P., Pandey, R., Garje, R. \& Chandra, A.B. Review of Indications of FDA-Approved Immune Checkpoint Inhibitors per NCCN Guidelines with the Level of Evidence. Cancers (Basel) 12(2020).

16. Naran, K., Nundalall, T., Chetty, S. \& Barth, S. Principles of Immunotherapy: Implications for Treatment Strategies in Cancer and Infectious Diseases. Front Microbiol 9, 3158 (2018).

17. Rao, M., Valentini, D., Dodoo, E., Zumla, A. \& Maeurer, M. Anti-PD-1/PD-L1 therapy for infectious diseases: learning from the cancer paradigm. Int J Infect Dis 56, 221-228 (2017).

18. Petrovas, C., et al. PD-1 is a regulator of virus-specific CD8+ T cell survival in HIV infection. J Exp Med 203, 2281-2292 (2006).

19. Day, C.L., et al. PD-1 expression on HIV-specific T cells is associated with T-cell exhaustion and disease progression. Nature 443, 350-354 (2006).

20. Velu, V., Shetty, R.D., Larsson, M. \& Shankar, E.M. Role of PD-1 co-inhibitory pathway in HIV infection and potential therapeutic options. Retrovirology 12, 14 (2015).

21. Sperk, M., Domselaar, R.V. \& Neogi, U. Immune Checkpoints as the Immune System Regulators and Potential Biomarkers in HIV-1 Infection. Int J Mol Sci 19(2018). 
medRxiv preprint doi: https://doi.org/10.1101/2021.12.22.21268218; this version posted December 30, 2021. The copyright holder for this preprint (which was not certified by peer review) is the author/funder, who has granted medRxiv a license to display the preprint in perpetuity.

All rights reserved. No reuse allowed without permission.

22. Hoffmann, M., et al. Exhaustion of Activated CD8 T Cells Predicts Disease Progression in Primary HIV-1 Infection. PLoS Pathog 12, e1005661 (2016).

23. Shive, C.L., et al. Inflammation Perturbs the IL-7 Axis, Promoting Senescence and Exhaustion that Broadly Characterize Immune Failure in Treated HIV Infection. J Acquir Immune Defic Syndr 71, 483-492 (2016).

24. Hurst, J., et al. Immunological biomarkers predict HIV-1 viral rebound after treatment interruption. Nat Commun 6, 8495 (2015).

25. Fromentin, R., et al. CD4+ T Cells Expressing PD-1, TIGIT and LAG-3 Contribute to HIV Persistence during ART. PLoS Pathog 12, e1005761 (2016).

26. Chomont, N., et al. HIV reservoir size and persistence are driven by $\mathrm{T}$ cell survival and homeostatic proliferation. Nat Med 15, 893-900 (2009).

27. Wightman, F., et al. Effect of ipilimumab on the HIV reservoir in an HIV-infected individual with metastatic melanoma. AIDS 29, 504-506 (2015).

28. Le Garff, G., et al. Transient HIV-specific T cells increase and inflammation in an HIVinfected patient treated with nivolumab. AIDS 31, 1048-1051 (2017).

29. Guihot, A., et al. Drastic decrease of the HIV reservoir in a patient treated with nivolumab for lung cancer. Ann Oncol 29, 517-518 (2018).

30. Polizzotto, M.N., Chen, G., Tressler, R.L. \& Godfrey, C. Leveraging Cancer Therapeutics for the HIV Cure Agenda: Current Status and Future Directions. Drugs 75, 1447-1459 (2015).

31. Davar, D., Wilson, M., Pruckner, C. \& Kirkwood, J.M. PD-1 Blockade in Advanced Melanoma in Patients with Hepatitis C and/or HIV. Case Rep Oncol Med 2015, 737389 (2015).

32. Gay, C.L., et al. Clinical Trial of the Anti-PD-L1 Antibody BMS-936559 in HIV-1 Infected Participants on Suppressive Antiretroviral Therapy. J Infect Dis 215, 1725-1733 (2017).

33. Riva, A. \& Chokshi, S. Immune checkpoint receptors: homeostatic regulators of immunity. Hepatol Int 12, 223-236 (2018).

34. Li, Y.M., et al. Soluble Tim-3 and Gal-9 are associated with renal allograft dysfunction in kidney transplant recipients: A cross-sectional study. Int Immunopharmacol 55, 330-335 (2018).

35. Chen, D., et al. Noninvasive detection of acute renal allograft rejection by measurement of soluble Tim-3 in urine. Mol Med Rep 16, 915-921 (2017).

36. Dahal, L.N., et al. Immunoregulatory soluble CTLA-4 modifies effector T-cell responses in systemic lupus erythematosus. Arthritis Res Ther 18, 180 (2016).

37. Ren, F., et al. Plasma soluble Tim-3 emerges as an inhibitor in sepsis: sepsis contrary to membrane Tim-3 on monocytes. Tissue Antigens 86, 325-332 (2015).

38. Simone, R., et al. The soluble form of CTLA-4 from serum of patients with autoimmune diseases regulates T-cell responses. Biomed Res Int 2014, 215763 (2014).

39. Casati, C., et al. Soluble human LAG-3 molecule amplifies the in vitro generation of type 1 tumor-specific immunity. Cancer Res 66, 4450-4460 (2006).

40. Haile, S.T., Horn, L.A. \& Ostrand-Rosenberg, S. A soluble form of CD80 enhances antitumor immunity by neutralizing programmed death ligand-1 and simultaneously providing costimulation. Cancer Immunol Res 2, 610-615 (2014).

41. Zhu, X. \& Lang, J. Soluble PD-1 and PD-L1: predictive and prognostic significance in cancer. Oncotarget 8, 97671-97682 (2017).

42. Heo, S.K., et al. The presence of high level soluble herpes virus entry mediator in sera of gastric cancer patients. Exp Mol Med 44, 149-158 (2012).

43. Gu, D., Ao, X., Yang, Y., Chen, Z. \& Xu, X. Soluble immune checkpoints in cancer: production, function and biological significance. J Immunother Cancer 6, 132 (2018).

44. Oaks, M.K. \& Hallett, K.M. Cutting edge: a soluble form of CTLA-4 in patients with autoimmune thyroid disease. J Immunol 164, 5015-5018 (2000). 
medRxiv preprint doi: https://doi.org/10.1101/2021.12.22.21268218; this version posted December 30, 2021. The copyright holder for this preprint (which was not certified by peer review) is the author/funder, who has granted medRxiv a license to display the preprint in perpetuity. All rights reserved. No reuse allowed without permission.

45. Li, W., et al. Immune Checkpoint Axes Are Dysregulated in Patients With Alcoholic Hepatitis. Hepatol Commun 4, 588-605 (2020).

46. Oaks, M.K., et al. A native soluble form of CTLA-4. Cell Immunol 201, 144-153 (2000).

47. Brunet, J.F., et al. A new member of the immunoglobulin superfamily--CTLA-4. Nature 328, 267-270 (1987).

48. Rowshanravan, B., Halliday, N. \& Sansom, D.M. CTLA-4: a moving target in immunotherapy. Blood 131, 58-67 (2018).

49. Esensten, J.H., Helou, Y.A., Chopra, G., Weiss, A. \& Bluestone, J.A. CD28 Costimulation: From Mechanism to Therapy. Immunity 44, 973-988 (2016).

50. Schall, T.J., et al. Molecular cloning and expression of a receptor for human tumor necrosis factor. Cell 61, 361-370 (1990).

51. Josimovic-Alasevic, O., Herrmann, T. \& Diamantstein, T. Demonstration of two distinct forms of released low-affinity type interleukin 2 receptors. Eur J Immunol 18, 1855-1857 (1988).

52. Mosley, B., et al. The murine interleukin-4 receptor: molecular cloning and characterization of secreted and membrane bound forms. Cell 59, 335-348 (1989).

53. Goodwin, R.G., et al. Cloning of the human and murine interleukin-7 receptors: demonstration of a soluble form and homology to a new receptor superfamily. Cell 60, 941-951 (1990).

54. Fernandez-Botran, R. Soluble cytokine receptors: their role in immunoregulation. FASEB J 5, 2567-2574 (1991).

55. Levine, S.J. Mechanisms of soluble cytokine receptor generation. J Immunol 173, 53435348 (2004).

56. Montgomery, R.I., Warner, M.S., Lum, B.J. \& Spear, P.G. Herpes simplex virus-1 entry into cells mediated by a novel member of the TNF/NGF receptor family. Cell 87, 427-436 (1996).

57. Rodriguez-Barbosa, J.I., et al. HVEM, a cosignaling molecular switch, and its interactions with BTLA, CD160 and LIGHT. Cell Mol Immunol 16, 679-682 (2019).

58. Zhu, Y., et al. Neuron-specific SALM5 limits inflammation in the CNS via its interaction with HVEM. Sci Adv 2, e1500637 (2016).

59. Riva, A., et al. Soluble TIM3 and Its Ligands Galectin-9 and CEACAM1 Are in Disequilibrium During Alcohol-Related Liver Disease and Promote Impairment of Antibacterial Immunity. Front Physiol 12, 632502 (2021).

60. Khan, M., Zhao, Z., Arooj, S., Fu, Y. \& Liao, G. Soluble PD-1: Predictive, Prognostic, and Therapeutic Value for Cancer Immunotherapy. Front Immunol 11, 587460 (2020).

61. Ng, K.W., et al. Soluble PD-L1 generated by endogenous retroelement exaptation is a receptor antagonist. Elife 8(2019).

62. Binnewies, M., et al. Understanding the tumor immune microenvironment (TIME) for effective therapy. Nat Med 24, 541-550 (2018).

63. Dong, M.P., et al. Clinical significance of circulating soluble immune checkpoint proteins in sorafenib-treated patients with advanced hepatocellular carcinoma. Sci Rep 10, 3392 (2020).

64. Cho, I., et al. Serum levels of soluble programmed death-ligand 1 (SPD-L1) in patients with primary central nervous system diffuse large B-cell lymphoma. BMC Cancer 20, 120 (2020).

65. Li, N., Jilisihan, B., Wang, W., Tang, Y. \& Keyoumu, S. Soluble LAG3 acts as a potential prognostic marker of gastric cancer and its positive correlation with CD8+T cell frequency and secretion of IL-12 and INF-gamma in peripheral blood. Cancer Biomark 23, 341-351 (2018). 
medRxiv preprint doi: https://doi.org/10.1101/2021.12.22.21268218; this version posted December 30, 2021. The copyright holder for this preprint (which was not certified by peer review) is the author/funder, who has granted medRxiv a license to display the preprint in perpetuity. All rights reserved. No reuse allowed without permission.

66. Li, F., et al. Highly elevated soluble Tim-3 levels correlate with increased hepatocellular carcinoma risk and poor survival of hepatocellular carcinoma patients in chronic hepatitis B virus infection. Cancer Manag Res 10, 941-951 (2018).

67. Simone, R., et al. A soluble form of CTLA-4 is present in paediatric patients with acute lymphoblastic leukaemia and correlates with CD1d+ expression. PLoS One 7, e44654 (2012).

68. Roselli, M., et al. Soluble CD40 ligand plasma levels in lung cancer. Clin Cancer Res 10, 610-614 (2004).

69. Caggiari, L., et al. High serum levels of soluble CD40-L in patients with undifferentiated nasopharyngeal carcinoma: pathogenic and clinical relevance. Infect Agent Cancer 2, 5 (2007).

70. Henn, V., et al. CD40 ligand on activated platelets triggers an inflammatory reaction of endothelial cells. Nature 391, 591-594 (1998).

71. Osada, J., Rusak, M., Kamocki, Z., Dabrowska, M.I. \& Kedra, B. Platelet activation in patients with advanced gastric cancer. Neoplasma 57, 145-150 (2010).

72. Mizoguchi, H., et al. Alterations in signal transduction molecules in T lymphocytes from tumor-bearing mice. Science 258, 1795-1798 (1992).

73. Huang, J., et al. Elevated serum soluble CD40 ligand in cancer patients may play an immunosuppressive role. Blood 120, 3030-3038 (2012).

74. Nielsen, C., Ohm-Laursen, L., Barington, T., Husby, S. \& Lillevang, S.T. Alternative splice variants of the human PD-1 gene. Cell Immunol 235, 109-116 (2005).

75. Elhag, O.A., et al. Reconstructed adeno-associated virus with the extracellular domain of murine PD-1 induces antitumor immunity. Asian Pac J Cancer Prev 13, 4031-4036 (2012).

76. Tan, Z., Chiu, M.S., Yan, C.W., Man, K. \& Chen, Z. Eliminating mesothelioma by AAVvectored, PD1-based vaccination in the tumor microenvironment. Mol Ther Oncolytics 20, 373-386 (2021).

77. Chakrabarti, R., Kapse, B. \& Mukherjee, G. Soluble immune checkpoint molecules: Serum markers for cancer diagnosis and prognosis. Cancer Rep (Hoboken) 2, e1160 (2019).

78. Fritz, J.M. \& Lenardo, M.J. Development of immune checkpoint therapy for cancer. J Exp Med 216, 1244-1254 (2019).

79. Kong, Y., et al. Storm of soluble immune checkpoints associated with disease severity of COVID-19. Signal Transduct Target Ther 5, 192 (2020).

80. Avendano-Ortiz, J., et al. The immune checkpoints storm in COVID-19: Role as severity markers at emergency department admission. Clin Transl Med 11, e573 (2021).

81. Yang, $X$., et al. Clinical course and outcomes of critically ill patients with SARS-CoV-2 pneumonia in Wuhan, China: a single-centered, retrospective, observational study. Lancet Respir Med 8, 475-481 (2020).

82. Ruan, Q., Yang, K., Wang, W., Jiang, L. \& Song, J. Clinical predictors of mortality due to COVID-19 based on an analysis of data of 150 patients from Wuhan, China. Intensive Care Med 46, 846-848 (2020).

83. Huang, C., et al. Clinical features of patients infected with 2019 novel coronavirus in Wuhan, China. Lancet 395, 497-506 (2020).

84. Giamarellos-Bourboulis, E.J., et al. Complex Immune Dysregulation in COVID-19 Patients with Severe Respiratory Failure. Cell Host Microbe 27, 992-1000 e1003 (2020).

85. Tan, L., et al. Lymphopenia predicts disease severity of COVID-19: a descriptive and predictive study. Signal Transduct Target Ther 5, 33 (2020).

86. Chen, G., et al. Clinical and immunological features of severe and moderate coronavirus disease 2019. J Clin Invest 130, 2620-2629 (2020). 
medRxiv preprint doi: https://doi.org/10.1101/2021.12.22.21268218; this version posted December 30, 2021. The copyright holder for this preprint (which was not certified by peer review) is the author/funder, who has granted medRxiv a license to display the preprint in perpetuity. All rights reserved. No reuse allowed without permission.

87. Huang, I. \& Pranata, R. Lymphopenia in severe coronavirus disease-2019 (COVID-19): systematic review and meta-analysis. J Intensive Care 8, 36 (2020).

88. Mathew, D., et al. Deep immune profiling of COVID-19 patients reveals distinct immunotypes with therapeutic implications. Science 369(2020).

89. Urra, J.M., Cabrera, C.M., Porras, L. \& Rodenas, I. Selective CD8 cell reduction by SARS-CoV-2 is associated with a worse prognosis and systemic inflammation in COVID-19 patients. Clin Immunol 217, 108486 (2020).

90. Tavakolpour, S., Rakhshandehroo, T., Wei, E.X. \& Rashidian, M. Lymphopenia during the COVID-19 infection: What it shows and what can be learned. Immunol Lett 225, 3132 (2020).

91. Reusch, N., et al. Neutrophils in COVID-19. Front Immunol 12, 652470 (2021).

92. Diao, B., et al. Reduction and Functional Exhaustion of T Cells in Patients With Coronavirus Disease 2019 (COVID-19). Front Immunol 11, 827 (2020).

93. Wan, S., et al. Relationships among lymphocyte subsets, cytokines, and the pulmonary inflammation index in coronavirus (COVID-19) infected patients. Br J Haematol 189, 428-437 (2020).

94. Vabret, N., et al. Immunology of COVID-19: Current State of the Science. Immunity 52, 910-941 (2020).

95. Pontelli, M.C., et al. Infection of human lymphomononuclear cells by SARS-CoV-2. bioRxiv (2020).

96. Chen, Z. \& John Wherry, E. T cell responses in patients with COVID-19. Nat ReV Immunol 20, 529-536 (2020).

97. Mudd, P.A., et al. Distinct inflammatory profiles distinguish COVID-19 from influenza with limited contributions from cytokine storm. Sci Adv 6(2020).

98. Scherger, S., Henao-Martinez, A., Franco-Paredes, C. \& Shapiro, L. Rethinking interleukin-6 blockade for treatment of COVID-19. Med Hypotheses 144, 110053 (2020).

99. Kox, M., Waalders, N.J.B., Kooistra, E.J., Gerretsen, J. \& Pickkers, P. Cytokine Levels in Critically III Patients With COVID-19 and Other Conditions. JAMA (2020).

100. Syed, F., et al. Excessive matrix metalloproteinase-1 and hyperactivation of endothelial cells occurred in COVID-19 patients and were associated with the severity of COVID-19. $J$ Infect Dis (2021).

101. Sinha, P., Matthay, M.A. \& Calfee, C.S. Is a "Cytokine Storm" Relevant to COVID-19? JAMA Intern Med 180, 1152-1154 (2020).

102. de Candia, P., Prattichizzo, F., Garavelli, S. \& Matarese, G. T Cells: Warriors of SARSCoV-2 Infection. Trends Immunol 42, 18-30 (2021).

103. Tian, S., et al. Pathological study of the 2019 novel coronavirus disease (COVID-19) through postmortem core biopsies. Mod Pathol 33, 1007-1014 (2020).

104. Liao, M., et al. Single-cell landscape of bronchoalveolar immune cells in patients with COVID-19. Nat Med 26, 842-844 (2020).

105. Wichmann, D., et al. Autopsy Findings and Venous Thromboembolism in Patients With COVID-19: A Prospective Cohort Study. Ann Intern Med 173, 268-277 (2020).

106. Chua, R.L., et al. COVID-19 severity correlates with airway epithelium-immune cell interactions identified by single-cell analysis. Nat Biotechnol 38, 970-979 (2020).

107. Avendano-Ortiz, J., et al. Soluble PD-L1: a potential immune marker for HIV-1 infection and virological failure. Medicine (Baltimore) 99, e20065 (2020).

108. Ara, A., Ahmed, K.A. \& Xiang, J. Multiple effects of CD40-CD40L axis in immunity against infection and cancer. Immunotargets Ther 7, 55-61 (2018).

109. Elgueta, R., et al. Molecular mechanism and function of CD40/CD40L engagement in the immune system. Immunol Rev 229, 152-172 (2009). 
medRxiv preprint doi: https://doi.org/10.1101/2021.12.22.21268218; this version posted December 30, 2021. The copyright holder for this preprint (which was not certified by peer review) is the author/funder, who has granted medRxiv a license to display the preprint in perpetuity. All rights reserved. No reuse allowed without permission.

110. Daub, S., Lutgens, E., Munzel, T. \& Daiber, A. CD40/CD40L and Related Signaling Pathways in Cardiovascular Health and Disease-The Pros and Cons for Cardioprotection. Int J Mol Sci 21(2020).

111. Kornbluth, R.S. The emerging role of CD40 ligand in HIV infection. J Leukoc Biol 68, 373-382 (2000).

112. Chougnet, C. Role of CD40 ligand dysregulation in HIV-associated dysfunction of antigen-presenting cells. J Leukoc Biol 74, $702-709$ (2003).

113. Garcia-Bates, T.M., et al. Contrasting Roles of the PD-1 Signaling Pathway in Dendritic Cell-Mediated Induction and Regulation of HIV-1-Specific Effector T Cell Functions. J Virol 93(2019).

114. Vonderheide, R.H. CD40 Agonist Antibodies in Cancer Immunotherapy. Annu Rev Med 71, 47-58 (2020).

115. Peters, A.L., Stunz, L.L. \& Bishop, G.A. CD40 and autoimmunity: the dark side of a great activator. Semin Immunol 21, 293-300 (2009).

116. Karnell, J.L., Rieder, S.A., Ettinger, R. \& Kolbeck, R. Targeting the CD40-CD40L pathway in autoimmune diseases: Humoral immunity and beyond. Adv Drug Deliv Rev 141, 92-103 (2019).

117. Aarts, S., et al. The CD40-CD40L Dyad in Experimental Autoimmune Encephalomyelitis and Multiple Sclerosis. Front Immunol 8, 1791 (2017).

118. del Rio, M.L., Lucas, C.L., Buhler, L., Rayat, G. \& Rodriguez-Barbosa, J.I. HVEM/LIGHT/BTLA/CD160 cosignaling pathways as targets for immune regulation. Journal of leukocyte biology 87, 223-235 (2010).

119. Rodriguez-Barbosa, J.I., et al. HVEM, a cosignaling molecular switch, and its interactions with BTLA, CD160 and LIGHT. Cellular \& molecular immunology (2019).

120. Cai, G. \& Freeman, G.J. The CD160, BTLA, LIGHT/HVEM pathway: a bidirectional switch regulating T-cell activation. Immunol Rev 229, 244-258 (2009).

121. Cai, G., et al. CD160 inhibits activation of human CD4+ T cells through interaction with herpesvirus entry mediator. Nat Immunol 9, 176-185 (2008).

122. Gowing, L.R., et al. Global statistics on addictive behaviours: 2014 status report. Addiction 110, 904-919 (2015).

123. Gilmore, W., et al. Alcohol: taking a population perspective. Nat Rev Gastroenterol Hepatol 13, 426-434 (2016).

124. O'Shea, R.S., Dasarathy, S., McCullough, A.J., Practice Guideline Committee of the American Association for the Study of Liver, D. \& Practice Parameters Committee of the American College of, G. Alcoholic liver disease. Hepatology 51, 307-328 (2010).

125. Mitchell, J. \& Dunlop, A. Alcohol consumption: monitoring, regulation and impact on public health. Public Health Res Pract 26(2016).

126. Wigg, S. \& Stafford, L.D. Health Warnings on Alcoholic Beverages: Perceptions of the Health Risks and Intentions towards Alcohol Consumption. PLoS One 11, e0153027 (2016).

127. WHO. HIV data and statistics. HIVIAIDS fact sheets (2021).

128. Justice, A., Sullivan, L., Fiellin, D. \& Veterans Aging Cohort Study Project, T. HIVIAIDS, comorbidity, and alcohol: can we make a difference? Alcohol Res Health 33, 258-266 (2010).

129. Meyerhoff, D.J. Effects of alcohol and HIV infection on the central nervous system. Alcohol Res Health 25, 288-298 (2001).

130. Monnig, M.A. Immune activation and neuroinflammation in alcohol use and HIV infection: evidence for shared mechanisms. Am J Drug Alcohol Abuse 43, 7-23 (2017).

131. Elamin, E., Masclee, A., Dekker, J. \& Jonkers, D. Ethanol disrupts intestinal epithelial tight junction integrity through intracellular calcium-mediated Rho/ROCK activation. Am J Physiol Gastrointest Liver Physiol 306, G677-685 (2014). 
medRxiv preprint doi: https://doi.org/10.1101/2021.12.22.21268218; this version posted December 30, 2021. The copyright holder for this preprint (which was not certified by peer review) is the author/funder, who has granted medRxiv a license to display the preprint in perpetuity. All rights reserved. No reuse allowed without permission.

132. Bode, C. \& Bode, J.C. Activation of the innate immune system and alcoholic liver disease: effects of ethanol per se or enhanced intestinal translocation of bacterial toxins induced by ethanol? Alcohol Clin Exp Res 29, 166S-171S (2005).

133. Gao, B. \& Bataller, R. Alcoholic liver disease: pathogenesis and new therapeutic targets. Gastroenterology 141, 1572-1585 (2011).

134. Pasala, S., Barr, T. \& Messaoudi, I. Impact of Alcohol Abuse on the Adaptive Immune System. Alcohol Res 37, 185-197 (2015).

135. Gao, B., et al. Innate immunity in alcoholic liver disease. Am J Physiol Gastrointest Liver Physiol 300, G516-525 (2011).

136. Miller, A.M., Horiguchi, N., Jeong, W.I., Radaeva, S. \& Gao, B. Molecular mechanisms of alcoholic liver disease: innate immunity and cytokines. Alcohol Clin Exp Res 35, 787-793 (2011).

137. Li, W., et al. Alcohol abstinence ameliorates the dysregulated immune profiles in patients with alcoholic hepatitis: A prospective observational study. Hepatology 66, 575-590 (2017).

138. Brenchley, J.M., et al. Microbial translocation is a cause of systemic immune activation in chronic HIV infection. Nat Med 12, 1365-1371 (2006).

139. Dinh, D.M., et al. Intestinal microbiota, microbial translocation, and systemic inflammation in chronic HIV infection. J Infect Dis 211, 19-27 (2015).

140. Puri, P., et al. The circulating microbiome signature and inferred functional metagenomics in alcoholic hepatitis. Hepatology 67, 1284-1302 (2018).

141. Liangpunsakul, S., et al. Quantity of alcohol drinking positively correlates with serum levels of endotoxin and markers of monocyte activation. Sci Rep 7, 4462 (2017).

142. Li, W., et al. Alcohol Abstinence Does Not Fully Reverse Abnormalities of MucosalAssociated Invariant T Cells in the Blood of Patients With Alcoholic Hepatitis. Clin Transl Gastroenterol 10, e00052 (2019).

143. Wong, E.B., Ndung'u, T. \& Kasprowicz, V.O. The role of mucosal-associated invariant T cells in infectious diseases. Immunology 150, 45-54 (2017).

144. Kurioka, A., Walker, L.J., Klenerman, P. \& Willberg, C.B. MAIT cells: new guardians of the liver. Clin Transl Immunology 5, e98 (2016).

145. Liangpunsakul, S., et al. Effects of Age, Sex, Body Weight, and Quantity of Alcohol Consumption on Occurrence and Severity of Alcoholic Hepatitis. Clin Gastroenterol Hepatol 14, 1831-1838 e1833 (2016). 
medRxiv preprint doi: https://doi.org/10.1101/2021.12.22.21268218; this version posted December 30, 2021. The copyright holder for this preprint (which was not certified by peer review) is the author/funder, who has granted medRxiv a license to display the preprint in perpetuity.

All rights reserved. No reuse allowed without permission.

Table 1. Plasma levels of sICPs in healthy adults

\begin{tabular}{|c|c|c|c|c|c|}
\hline $\begin{array}{l}\text { Stimulatory } \\
\text { ICPs }\end{array}$ & $\begin{array}{l}\text { Healthy adults } \\
(n=34-39)\end{array}$ & $\begin{array}{l}\text { Sensitivity } \\
\text { (pg/mL) }\end{array}$ & $\begin{array}{l}\text { Inhibitory } \\
\text { ICPS }\end{array}$ & $\begin{array}{l}\text { Healthy adults } \\
(n=34-39)\end{array}$ & $\begin{array}{c}\text { Sensitivity } \\
(\mathrm{pg} / \mathrm{mL})\end{array}$ \\
\hline CD27 & $\begin{array}{c}881 \\
(603-1,180)\end{array}$ & 24.1 & BTLA & $\begin{array}{c}370 \\
(139-668)\end{array}$ & 43.8 \\
\hline CD28 & $\begin{array}{c}108 \\
(496-2,106)\end{array}$ & 84.5 & CD160 & $\begin{array}{c}5,590 \\
(3,801-10,605)\end{array}$ & 93.8 \\
\hline CD40 & $\begin{array}{c}285 \\
(148-385) \\
\end{array}$ & 4.3 & CTLA-4 & $\begin{array}{c}31 \\
(12-81) \\
\end{array}$ & 9.3 \\
\hline CD80 & $\begin{array}{c}21 \\
(13-31)\end{array}$ & 11.2 & HVEM & $\begin{array}{c}1,197 \\
(885-1,651)\end{array}$ & 0.8 \\
\hline CD86 & $\begin{array}{c}718 \\
(457-1,228)\end{array}$ & 86.1 & LAG-3 & $\begin{array}{c}3,459 \\
(2,120-4,852)\end{array}$ & 66.0 \\
\hline GITR & $\begin{array}{c}16 \\
(6-48)\end{array}$ & 18.8 & PD-1 & $\begin{array}{c}361 \\
(219-744)\end{array}$ & 13.7 \\
\hline GITRL & $\begin{array}{c}169 \\
(81-427)\end{array}$ & 20.5 & PD-L1 & $\begin{array}{c}19 \\
(10-41)\end{array}$ & 1.3 \\
\hline ICOS & $\begin{array}{c}370 \\
(139-668)\end{array}$ & 55.6 & TIM-3 & $\begin{array}{c}1,228 \\
(1,021-1,875)\end{array}$ & 1.5 \\
\hline LIGHT & $\begin{array}{c}240 \\
(39-1,274) \\
\end{array}$ & 62.5 & & & \\
\hline TLR-2 & $\begin{array}{c}466 \\
(286-935)\end{array}$ & 24.1 & & & \\
\hline
\end{tabular}

Note: Data are represented as median and (interquartile ranges) in $\mathrm{pg} / \mathrm{mL}$. Characteristics of study subjects were described in our previous report ${ }^{45}$. 
medRxiv preprint doi: https://doi.org/10.1101/2021.12.22.21268218; this version posted December 30, 2021. The copyright holder for this preprint (which was not certified by peer review) is the author/funder, who has granted medRxiv a license to display the preprint in perpetuity.

All rights reserved. No reuse allowed without permission.

Table 2. Plasma levels of sICPs in heavy alcohol users with HIV infection

\begin{tabular}{|c|c|c|c|c|}
\hline sICP & HDC $(n=26)$ & HIV $(n=28)$ & $H D C+H I V(n=21)$ & $P$ value \\
\hline sBTLA & $2,89(126-533)$ & $336(203-453)$ & 650 (407-948) & ${ }^{\mathrm{ns}} P 1,{ }^{* * *} P 2,{ }^{* *} P 3$ \\
\hline sCD27 & $1,375(746-1,855)$ & $1,701(697-3,244)$ & $1,727(805-4,214)$ & ${ }^{\mathrm{ns}} P 1,{ }^{\mathrm{ns}} P 2,{ }^{\mathrm{ns}} P 3$ \\
\hline sCD28 & $1,201(341-2,481)$ & $1,254(665-1,979)$ & $3,043(1,796-5,934)$ & ${ }^{\mathrm{ns}} P 1,{ }^{* *} P 2,{ }^{* *} P 3$ \\
\hline sTIM-3 & $1,789(1,240-2,526)$ & $2,023(1,084-2,348)$ & $2,715(1,529-3,339)$ & ${ }^{\mathrm{ns}} P 1,{ }^{\mathrm{ns}} P 2,{ }^{\mathrm{ns}} P 3$ \\
\hline sHVEM & $1,809(762-2,385)$ & $2,208(1,980-2,808)$ & $3,723(2,459-5,148)$ & ${ }^{\mathrm{ns}} \mathrm{P} 1,{ }^{* * *} \mathrm{P} 2,{ }^{*} \mathrm{P} 3$ \\
\hline sCD40 & $589(158-706)$ & $643(439-815)$ & $1,207(909-1,519)$ & ${ }^{\mathrm{ns}} P 1,{ }^{* * *} P 2,{ }^{* * *} P 3$ \\
\hline sLAG-3 & $3,138(1$, & $3,932(1,688-5,632)$ & $7,282(4,232$ & ${ }^{\mathrm{ns}} \mathrm{P} 1,{ }^{* *} P 2,{ }^{* *} P 3$ \\
\hline sTLR-2 & $579(44-165)$ & $788(554-1,027)$ & $1,437(1,067-1,739)$ & ${ }^{\mathrm{ns}} P 1,{ }^{* * *} P 2,{ }^{* * *} P 3$ \\
\hline sGITRL & $123(140-905)$ & $120(85-178)$ & $245(163-345)$ & ${ }^{\mathrm{ns}} P 1,{ }^{* * *} P 2,{ }^{* * *} P 3$ \\
\hline sPD-1 & 647 (201-980) & $675(467-1,148)$ & $1,962(1,206-2,290)$ & ${ }^{\mathrm{ns}} P 1,{ }^{* * *} P 2,{ }^{* * *} P 3$ \\
\hline sCTLA-4 & $78(16-124)$ & $56(19-99)$ & $250(142-386)$ & ${ }^{\mathrm{ns}} P 1,{ }^{* * *} P 2,{ }^{* * *} P 3$ \\
\hline sCD80 & $30(17-45)$ & $34(18-45)$ & $51(28-77)$ & ${ }^{\mathrm{ns}} P 1,{ }^{* *} P 2,{ }^{*} P 3$ \\
\hline sCD86 & $870(222-1,619)$ & $912(673-1,585)$ & $2,521(1,355-3,747)$ & ${ }^{\mathrm{ns}} P 1,{ }^{* * *} P 2,{ }^{* *} P 3$ \\
\hline sPD-L1 & $30(10-51)$ & $29(20-48)$ & $65(46-90)$ & ${ }^{\mathrm{ns}} P 1,{ }^{* * *} P 2,{ }^{* * *} P 3$ \\
\hline sGITR & $86(0-291)$ & $21(0-137)$ & 696 (332-935) & ${ }^{\mathrm{ns}} P 1,{ }^{* * *} P 2,{ }^{* * *} P 3$ \\
\hline sICOS & $166(52-296)$ & 205 (134-269) & $340(242-450)$ & ${ }^{\mathrm{ns}} P 1,{ }^{* * *} P 2,{ }^{* * *} P 3$ \\
\hline
\end{tabular}

Note: Data are represented as median (interquartile range). Kruskal-Wallis test with Dunn's corrections was used to calculate differences among 3 groups of HDCs, HIV, and HDC+HIV. HDCs, heavy alcohol drinkers without overt liver disease; HIV, people living with HIV (PLHIV) on antiviral therapy (ART); HDC+HIV, HDCs with HIV infection on ART, but without overt liver disease. P1, statistical analysis between HDC and HIV; P2, statistical analysis between HDC and HDV+HIV; $P 3$, statistical analysis between HIV and HDC+HIV. ${ }^{\text {ns }} P$, no significant; ${ }^{*} P 0.05$; ${ }^{\star \star} P<0.01 ;{ }^{* \star} P<0.001$. Detailed definitions of HDC and the inclusion and exclusion criteria were previously described ${ }^{137,145}$. 


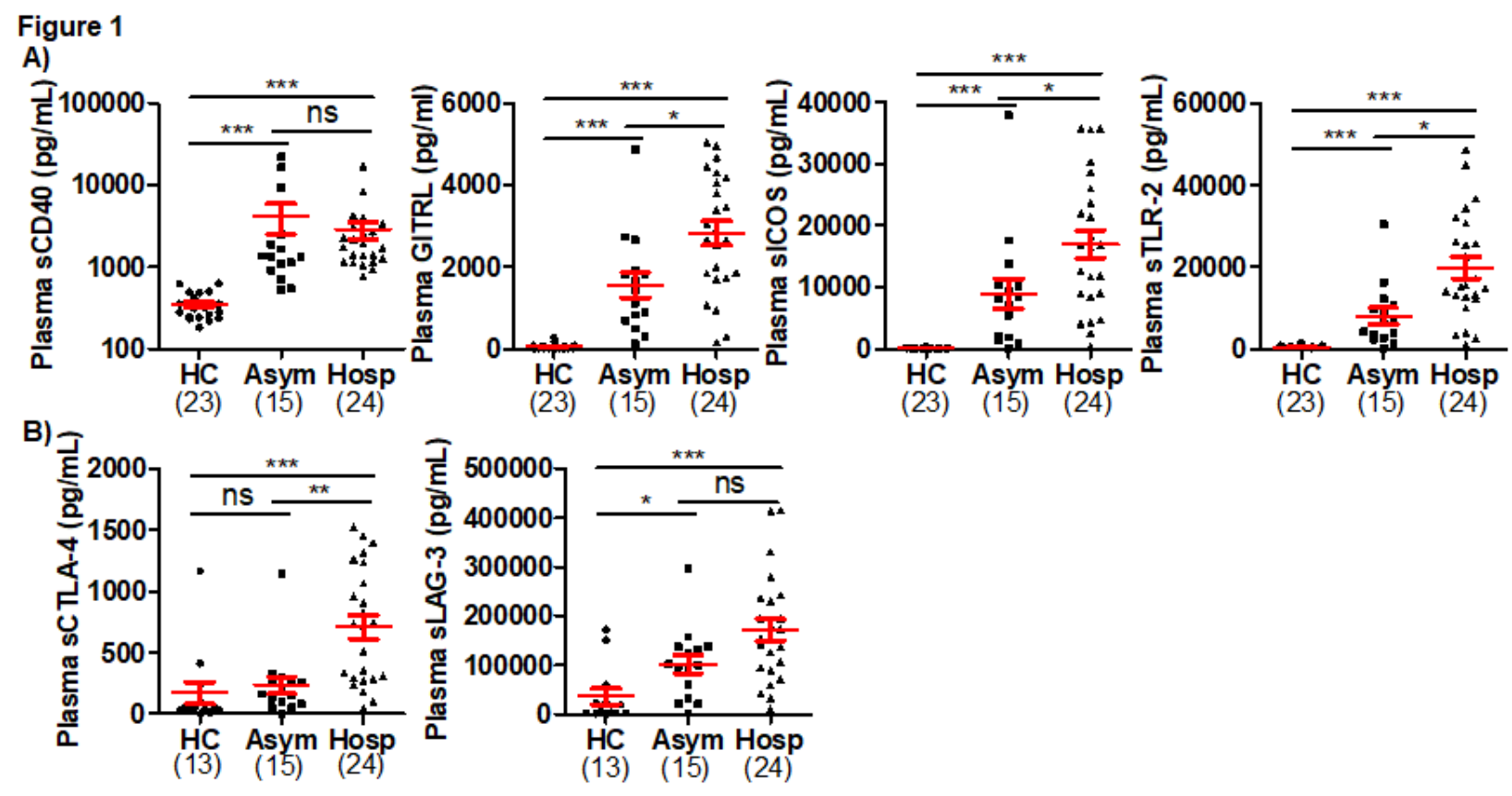

Figure 1. Plasma levels of sICPs were highly elevated in COVID-19. A) Scatter plots demonstrating the plasma levels of 4 sICPs that were not previously studied in COVID-19. B) Scatter plots demonstrating the plasma levels of 2 SICPs in COVID-19 that were previously reported with different results. Kruskal-Wallis test with Dunn's corrections for pairwise comparisons among hospitalized (severe/critical) COVID-19 patients (Hosp), SARS-CoV-2infected individuals without symptoms (Asym), and healthy controls (HCs). Red lines represent the mean and the standard error of the mean. ns, no significant; ${ }^{*} p<0.05 ;{ }^{* \star} p<0.01 ;{ }^{* \star} p<0.001$. 
medRxiv preprint doi: https://doi.org/10.1101/2021.12.22.21268218; this version posted December 30, 2021. The copyright holder for this preprint (which was not certified by peer review) is the author/funder, who has granted medRxiv a license to display the preprint in perpetuity.

Figure 2
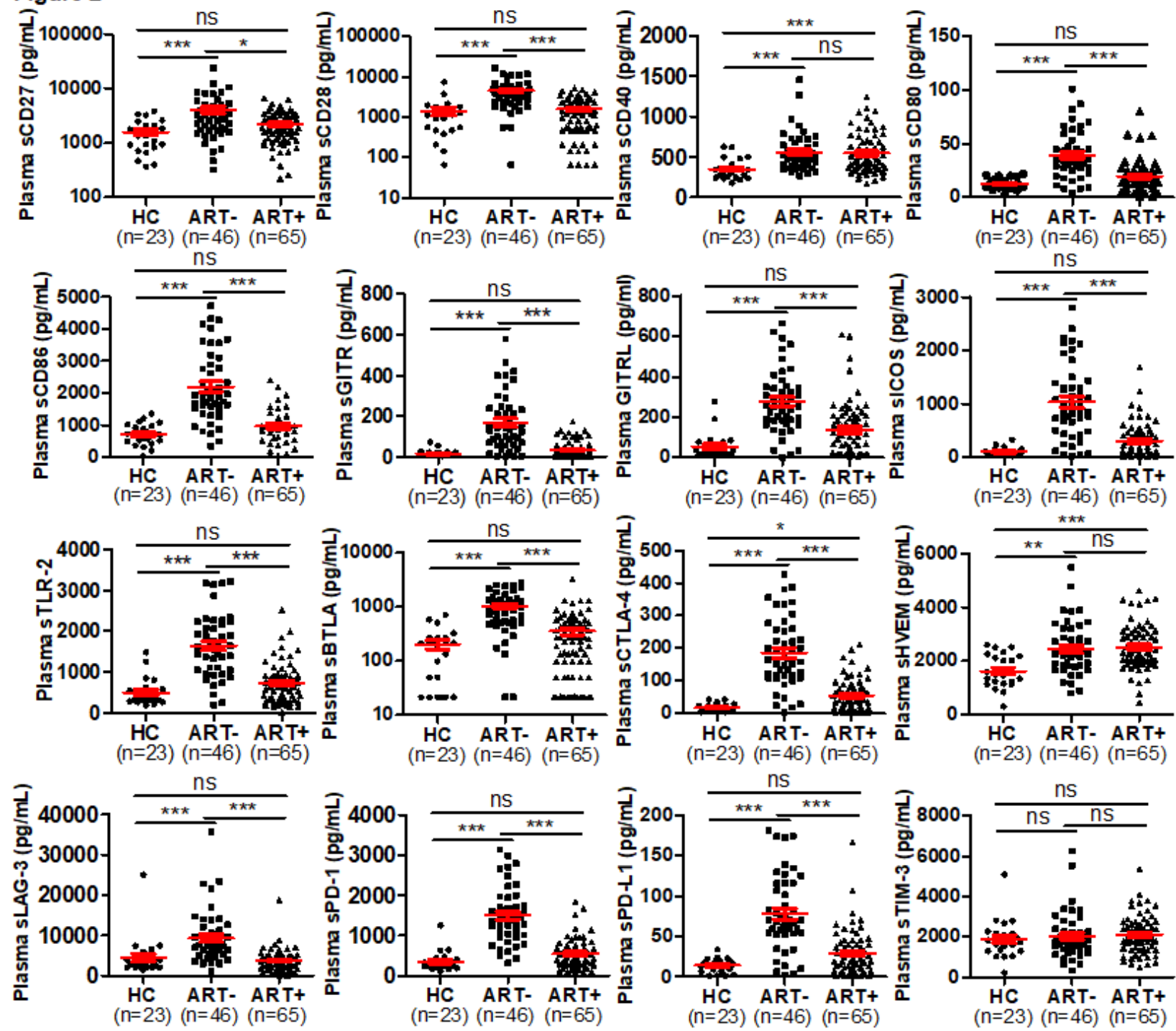

Figure 2. Plasma levels of sICPs were highly dysregulated in PLHIV. Scatter plots

demonstrating the plasma levels of sICPs in HCs (healthy controls), ART-naïve PLHIV, and

PLHIV on ART. Kruskal-Wallis test with Dunn's corrections for pairwise comparisons among

PLHIV on ART, ART-naïve PLHIV, and HCs. Red lines represent the mean and the standard

error of the mean. ns, no significant; ${ }^{*} p<0.05 ;{ }^{* \star} p<0.01$; ${ }^{\star \star *} p<0.001$. Abbreviations: HC, healthy

control; ART-, people living with HIV (PLHIV) who were not treated with antiretroviral therapy

(ART); and ART+, people living with HIV (PLHIV) who were treated with antiretroviral therapy

(ART). 